\title{
вмJ Global Health Towards resilient health systems: opportunities to align surgical and disaster planning
}

To cite: Pyda J, Patterson RH, Caddell L, et al. Towards resilient health systems: opportunities to align surgical and disaster planning. BMJ Global Health 2019;4:e001493. doi:10.1136/ bmjgh-2019-001493

Handling editor Seye Abimbola JP and RHP are joint first authors.

Received 11 February 2019 Revised 8 May 2019 Accepted 11 May 2019
Check for updates

(c) Author(s) (or their employer(s)) 2019. Re-use permitted under CC BY-NC. No commercial re-use. See rights and permissions. Published by BMJ.

For numbered affiliations see end of article.

Correspondence to Dr Jordan Pyda; jordanpyda@gmail.com

\section{ABSTRACT}

Natural disasters significantly contribute to human death and suffering. Moreover, they exacerbate pre-existing health inequalities by imposing an additional burden on the most vulnerable populations. Robust local health systems can greatly mitigate this burden by absorbing the extraordinary patient volume and case complexity immediately after a disaster. This resilience is largely determined by the predisaster local surgical capacity, with trauma, neurosurgical, obstetrical and anaesthesia care of particular importance. Nevertheless, the disaster management and global surgery communities have not coordinated the development of surgical systems in low/ middle-income countries (LMIC) with disaster resilience in mind. Herein, we argue that an appropriate peridisaster response requires coordinated surgical and disaster policy, as only local surgical systems can provide adequate disaster care in LMICs.

We highlight three opportunities to help guide this policy collaboration. First, the Lancet Commission on Global Surgery and the Sendai Framework for Disaster Risk Reduction set forth independent roadmaps for global surgical care and disaster risk reduction; however, ultimately both advocate for health system strengthening in LMICs. Second, the integration of surgical and disaster planning is necessary. Disaster risk reduction plans could recognise the role of surgical systems in disaster preparedness more explicitly and pre-emptively identify deficiencies in surgical systems. Based on these insights, National Surgical, Obstetric, and Anesthesia Plans, in turn, can better address deficiencies in systems and ensure increased disaster resilience. Lastly, the recent momentum for national surgical planning in LMICs represents a political window for the integration of surgical policy and disaster risk reduction strategies.

\section{INTRODUCTION}

Natural disasters have been a source of death and suffering throughout human history. Over the last few centuries, trends in industrialisation and urbanisation have led to a dramatic growth in the world population which is largely concentrated in cities. Concurrently, climate change has been
Summary box

- Natural disasters affected over 95 million people in 2017, contributing to an estimated 68000 deaths and over US\$335 billion in economic losses worldwide. ${ }^{2}$

- Disaster risk reduction (DRR) strategies are plans designed to minimise these negative effects and to promote the resiliency of local health systems. ${ }^{5}$

- Despite the overwhelming need for surgical care in postdisaster settings, DRR plans have not effectively prioritised surgical systems planning.

- National Surgical, Obstetric, and Anesthesia Plans (NSOAPs) are a novel framework for the development of surgical care systems being adapted by many countries.

- Together, NSOAPs and DRR strategies represent an opportunity to coordinate more comprehensive surgical care policy and to build resilient health systems.

linked to the increased frequency and intensity of natural hazards such as earthquakes, floods and storms. ${ }^{1-3}$ When natural hazards disrupt human life or activity they become natural disasters. ${ }^{4}$ Most recently, between 2007 and 2016, approximately 354 natural disasters affected an average of 210 million people per year worldwide and contributed to an estimated 68000 annual deaths. ${ }^{5}$ In addition to the human losses, disasters can paralyse regional development. ${ }^{6}$ Loss of life and destruction of infrastructure have contributed to approximately US $\$ 142$ billion in annual economic losses during this time period. ${ }^{5}$ In 2017 , the annual losses surpassed US $\$ 300$ billion. ${ }^{3} 5$ This places a growing number of people at heightened physical and financial risk. ${ }^{7}$

Furthermore, it is clear that natural disasters impose an additional burden on the most vulnerable populations and thus exacerbate pre-existing health inequalities. Women, children, the elderly and those 
of lower socioeconomic status are most affected. ${ }^{8}{ }^{9}$ As such, natural disasters are not natural in that the loss of life and health largely depends on man-made and societal factors; in fact, socioeconomic disparity acts as a more powerful driver of health outcomes than the natural disasters themselves. ${ }^{8}$ Thus, while natural hazards may be inevitable, the extent of the resulting human tragedy during natural disasters can, in fact, be mitigated.

Differences in health outcomes after disasters can be reduced by appropriate preparation and response. Functional, efficient health systems are better able to absorb the extraordinary volume and complexity of patients immediately after a disaster. ${ }^{3}$ Yet, the resource-intensive response required in crisis situations stresses the extant health system. In resource-limited settings where additional resources, personnel and infrastructure cannot be readily mobilised this becomes a major limitation to the care of victims. Additionally, acute trauma may require complex management including surgery, intensive care and other higher resource interventions. Thus, the worst health outcomes during disasters are seen in settings with constrained availability of staff, operating rooms and intensive care units ${ }^{10}{ }^{11}$-a quotidian reality in most low/middle-income countries (LMIC). ${ }^{12}$ Furthermore, health systems without sufficient baseline surgical capacity are more prone to dysfunction in disasters, ${ }^{13}$ meaning that surgical care for cancer, caesarean sections, routine emergencies and other conditions is interrupted. ${ }^{14-16}$

Despite this predictable and recurrent deficiency, disaster management and global surgery policymakers have not coordinated the development of surgical systems with disaster resilience in mind. However, a potential starting point exists: key guiding frameworks offer synergistic goals and overlapping recommendations. The Sendai Framework for Disaster Risk Reduction, developed in 2015 by the United Nations Office for Disaster Risk Reduction, focuses on improving disaster resilience. ${ }^{5}$ That same year, the Lancet Commission on Global Surgery (LCoGS) published the Global Surgery 2030 report which established a path for surgical system development in LMICs. ${ }^{12}$ While redefining each respective field, these landmark contributions are not being collaboratively implemented despite significant conceptual overlap. There are ongoing efforts to link a number of other health domains with the Sendai Framework, including mental and public health. ${ }^{17} 18$

In this article, we argue the central importance of developing local surgical capacity as part of disaster risk reduction (DRR). We review the relevant modern history of disaster management and global surgery with an eye for common objectives. Lastly, we propose key opportunities to coordinate policy that will strengthen local surgical systems, develop more robust disaster preparedness and reduce the impact of disasters on the most vulnerable populations.
THE ROLE OF LOCAL SURGICAL CAPACITY

In many LMICs, foreign medical teams (FMT) have historically filled critical human and infrastructure resource gaps in the postdisaster period. FMTs typically arrive too late to assist in the initial response which occurs in the first hours and days after a disaster event; a delay which commensurately increases with destruction of local infrastructure. ${ }^{19}$ Disaster victims with life-threatening surgical conditions often do not survive beyond this period, and FMTs primarily treat less acute forms of medical and surgical disease. ${ }^{16}{ }^{20}$ Historically, LMICs have had to rely on disaster response by FMTs despite the reality that successful management of the most pressing injuries depends on the ability of local health systems to provide timely, affordable and quality surgical care. The vulnerability of relying on FMTs has been recognised by both the United Nations (UN) ${ }^{21}$ and the WHO, which recently noted that 'the most timely and cost effective response to trauma is the one mobilized by the affected country itself. ${ }^{, 22}$ Given the propensity of disasters to cause surgical trauma, robust local surgical systems in LMICs are imperative in order to address the primary surge of patients so that people do not die of treatable conditions. $^{23} 24$

The 2015 Nepal earthquake is an example of the need for local surgical capacity in postdisaster response. On 25 April 2015, a $7.8 \mathrm{M}_{\mathrm{w}}$ (moment magnitude) earthquake struck about $80 \mathrm{~km}$ from Kathmandu, the capital city. ${ }^{25}$ Giri et al report on the surgical experience during the first 21 days at Dhulikhel Hospital, a university hospital with 375 beds. On the day of the earthquake, injured people streamed into the hospital. The immense medical need forced the Dhulikhel Hospital staff to use all inpatient beds and house overflow patients in a crowded courtyard space. During the ensuing 3 weeks, Dhulikhel Hospital registered 2003 emergency patients of which 758 were admitted as inpatients. The local surgical team performed 345 surgeries, the majority of which were orthopaedic procedures. ${ }^{16}$

Distance, remote location and other geographical impasses contributed to travel delays; FMTs were not able to provide assistance during the immediate postdisaster period. In fact, international field hospitals were unable to begin treating patients until 3 days after the earthquake. Thus, most patients who suffered critical injuries requiring timely treatment were entirely dependent on the local capacity at Dhulikhel Hospital. However, the extraordinary efforts of the Dhulikhel Hospital staff were often hindered by limitations in baseline capacity. For example, the hospital did not offer neurosurgical services, necessitating the transfer of eight patients with head injuries to a hospital in Kathmandu. Furthermore, the staff also faced challenges coordinating care within the healthcare system due to disruption of communication and transportation infrastructure. This limited the ability to coordinate transfers and external care for patients, requiring the hospital to depend exclusively on internal staffing and supplies to provide 24 hours 
of surgical services on-site. Giri et al highlight that a key lesson learnt from this event is recognising the importance of developing consistent and robust local health services capable of managing natural disasters. ${ }^{, 16}$

Data from Rodriguez-Llanes et al further illustrate this need by quantifying the financial implications of local surgical care. They report on the response to a 2008 earthquake of comparable intensity $\left(7.9 \mathrm{M}_{\mathrm{w}}\right)$ in Wenchuan, China, and estimate that during the first 20 days after earthquake, surgical management at People's Hospital of Deyang City (PHDC) averted 42\% (4379 disability-adjusted life years) of the burden of injury for 1861 patients. They analysed the economic impact of surgical care provided at PHDC, calculating that surgery averted an economic loss of $\$ 15.2$ million in disability and death from injuries. ${ }^{26}$ Their work demonstrates that surgical care reduces the health-related burden of traumatic surgical disease and reduces the economic impact of disasters. Comparable postdisaster experiences in Haiti and elsewhere in China emphasise the need for a robust local surgical system response and have been reported previously in the disaster literature. ${ }^{27} 28$

\section{THE MODERN HISTORY OF DISASTER MANAGEMENT AND GLOBAL SURGERY POLICY}

A brief review of the modern history of the disaster management and global surgery fields reveals the evolution of thinking around health system strengthening for disasters. Specifically, we highlight shifts in priorities and key policy developments that have created this shared focus. Figure 1 presents a timeline of key events.

\section{Disaster management policy}

Disaster management policy at the UN originated in the aftermath of the 1962 Buin Zahra earthquake in Iran. This devastating event caused 12225 fatalities and prompted the international community to organise around disaster response. Without prior structures in place, the UN passed a resolution over a month after the catastrophe, finally calling on member states to consider providing aid to Iran. ${ }^{29}$ This was the first UN resolution pertaining to a disaster, and it set the paradigm for disaster management policy for the next decades.

In 1971, the UN formed the United Nations Disaster Relief Office (UNDRO), which was designed to coordinate international organisations involved in disaster management. The initial goals of the UNDRO focused on providing relief immediately after disasters and contributed little to disaster preparation. ${ }^{30}$ Nevertheless, growing experience in disaster response pushed the UN to recognise the need for disaster preparation. In 1970s and early 1980s, the UN prioritised early warning systems to decrease postdisaster response times. ${ }^{2130}$ This culminated in 1987 when the UN General Assembly introduced language of predisaster preparation, effectively establishing a new lexicon for disaster preparedness. ${ }^{31}$ Definitions of key terms now in use are presented in table 1.

The 1990s were deemed the 'International Decade of Natural Disaster Reduction' as members of the field came to understand that 'disaster response alone is not sufficient, as it yields only temporary results at a very high cost. ${ }^{32}$ This mandate marked the beginning of a mindset shift in disaster management. Research and advocacy turned towards preventing human catastrophe through specific improvements in predisaster planning, such as attempting to develop comprehensive national disaster plans and mobilising resources for disaster management. ${ }^{32}$ As the world moved into the new millennium, then UN Secretary General Kofi Annan emphasised the need to expand prevention efforts and reduce vulnerabilities, declaring that 'disaster prevention is a moral imperative. ${ }^{33}$

In the early 2000 s, the UN turned attention to the fact that more vulnerable systems fared worse during disasters, prompting the UN General Assembly to call for a focus on building local capacity in addition to strengthening existing disaster preparedness and response measures. ${ }^{34}$ In 2004, this was termed 'health systems resilience,' which encompasses the adaptability of a health system to resist or respond to external forces like natural hazards, and the effectiveness with which it draws on

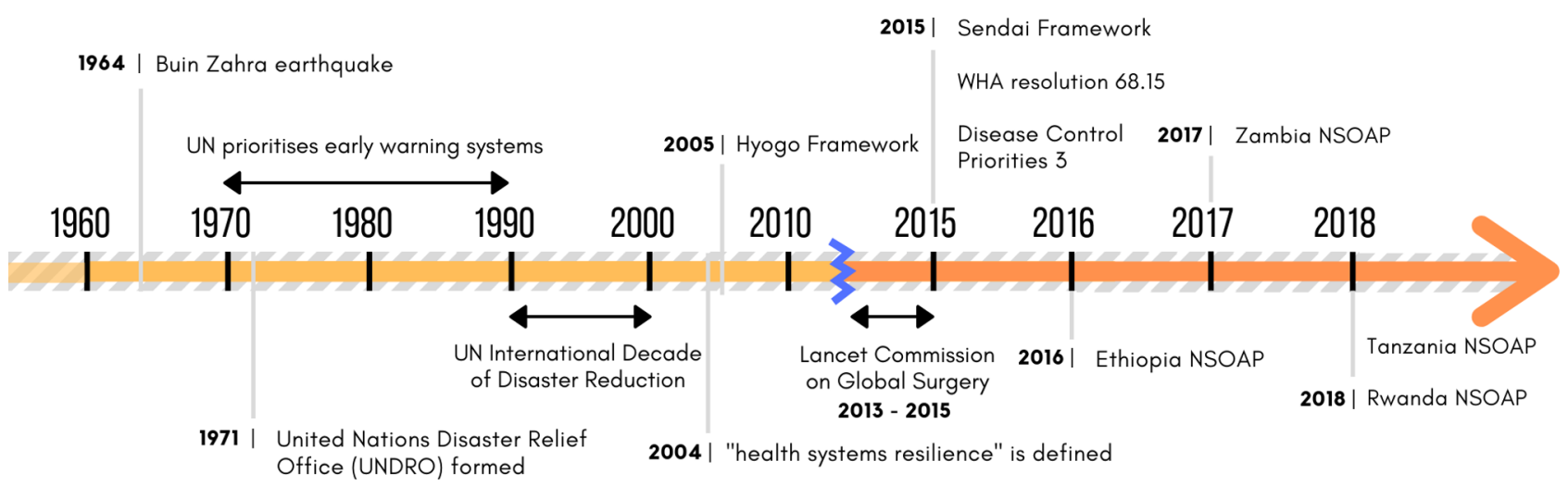

Figure 1 Timeline of key events in disaster management and global surgery policy since 1960. NSOAP, National Surgical, Obstetric, and Anesthesia Plans; UN, United Nations; WHA, World Health Assembly. 
Table 1 Key definitions as developed by UNISDR and LCoGS

\section{Key definitions}

\begin{tabular}{ll}
\hline Disaster & $\begin{array}{l}\text { 'A serious disruption of the functioning of a community or a society at any scale due to hazardous } \\
\text { events interacting with conditions of exposure, vulnerability and capacity, leading to one or more } \\
\text { of the following: human, material, economic and environmental losses and impacts.' }\end{array}$ \\
Health system resilience & $\begin{array}{l}\text { 'The ability of a system, community or society exposed to hazards to resist, absorb, } \\
\text { accommodate, adapt to, transform and recover from the effects of a hazard in a timely and } \\
\text { efficient manner, including through the preservation and restoration of its essential basic } \\
\text { structures and functions through risk management.' }\end{array}$ \\
National surgical planning & $\begin{array}{l}\text { Policymaking process by which national governments and key stakeholders develop National } \\
\text { Surgical, Obstetric, and Anesthesia Plans. }\end{array}$ \\
Disaster risk reduction & $\begin{array}{l}\text { 'Disaster risk reduction is aimed at preventing new and reducing existing disaster risk and } \\
\text { managing residual risk, all of which contribute to strengthening resilience and therefore to the } \\
\text { achievement of sustainable development.'4 }\end{array}$ \\
\hline
\end{tabular}

LCoGS, Lancet Commission on Global Surgery; UNISDR, United Nations Office for Disaster Risk Reduction.

these experiences to build its capacity to minimise the impact of future disasters. ${ }^{35}$

UN recommendations from the mid-2000s emphasised resilience of healthcare systems in resource-constrained settings, recognising the need to minimise the impact of disasters in order to reduce poverty and achieve development goals. ${ }^{36} 37$ These recommendations were incorporated in the 2005 Hyogo framework and subsequently prioritised in the 2015 Sendai Framework through an explicit call to shift funding towards health systems resilience building. One of the key mechanisms proposed by the Sendai Framework to achieve resilient systems is the development of DRR strategies, which are national plans designed to build disaster resilience across multiple sectors in a country. ${ }^{5}$

Much of the literature on resilience building focuses on the prehospital and emergency components of health system strengthening. ${ }^{38}$ Despite a plethora of publications narrating the surgical response, systematic reporting of the burden of surgical injuries after disasters is largely absent from the literature. ${ }^{1619}$ Surgical disease, like extremity soft tissue injuries and bone fractures, is inherently tied to the mechanisms of physical injury in the most devastating disasters, ${ }^{40}$ but the disaster management community has yet to highlight its importance via the Sendai Framework.

\section{Global surgery policy}

Historically, the majority of the global surgery community has had little focus on healthcare systems development. FMTs have been the de facto method for addressing the surgical burden of disease in both acute postdisaster and long-term care situations. However, the LCoGS and a WHO resolution have challenged the global surgery stakeholders to redefine their role in the development of surgical care. ${ }^{12}$

In 2015, recognising that over 100 million people sustain injuries each year, the World Health Assembly passed resolution 68.15 which affirmed the critical role of emergency and essential surgical and anaesthesia care in comprehensive health systems. ${ }^{41}$ That year also saw the publication of the Disease Control Priorities Third Edition, Volume 1, and LCoGS Global Surgery 2030 report which quantified the global burden of surgical disease and introduced metrics for addressing this need. $^{12} 42$

Approximately 5 billion people do not have access to safe, timely and affordable surgical and anaesthesia care, despite the fact that $30 \%$ of the total global burden of disease is amenable to surgical care. ${ }^{1243}$ Recognising that an FMT-dependent approach cannot meet this need, the LCoGS argued that surgery is an 'indivisible, indispensable part of healthcare' and must be scaled up within existing health systems to prevent unnecessary disability and death. ${ }^{44}$ To facilitate this growth, the LCoGS outlined the policy process of national surgical planning to integrate surgical systems within existing national healthcare policy. $^{12}$

Following this framework, Ethiopia, Zambia, Tanzania and Rwanda have developed and signed National Surgical, Obstetric, and Anesthesia Plans (NSOAPs), ${ }^{45-49}$ with many more NSOAPs in the early stages of development. ${ }^{48}$ These national policies set priorities and outline the steps necessary to advance local surgical capacity. ${ }^{12}$ Figure 2 summarises the current status of NSOAP development worldwide. Despite highlighting the essential role of surgery within comprehensive health systems, the global surgery community has not yet integrated disaster preparedness and health system resilience into NSOAPs. While each NSOAP includes language about trauma, none of the four publicly available NSOAPs directly address the role of surgical care in disasters. Previous national surgical planning processes have been conducted in countries without frequent disasters, but the unpredictable nature of disasters necessitates planning for them in future NSOAPs. ${ }^{45-49}$

\section{CONVERGING PRIORITIES}

Actors from both surgical and disaster management fields have identified that populations suffer unnecessarily in the wake of disasters when surgical capacity is inadequate. ${ }^{13} 16$ 


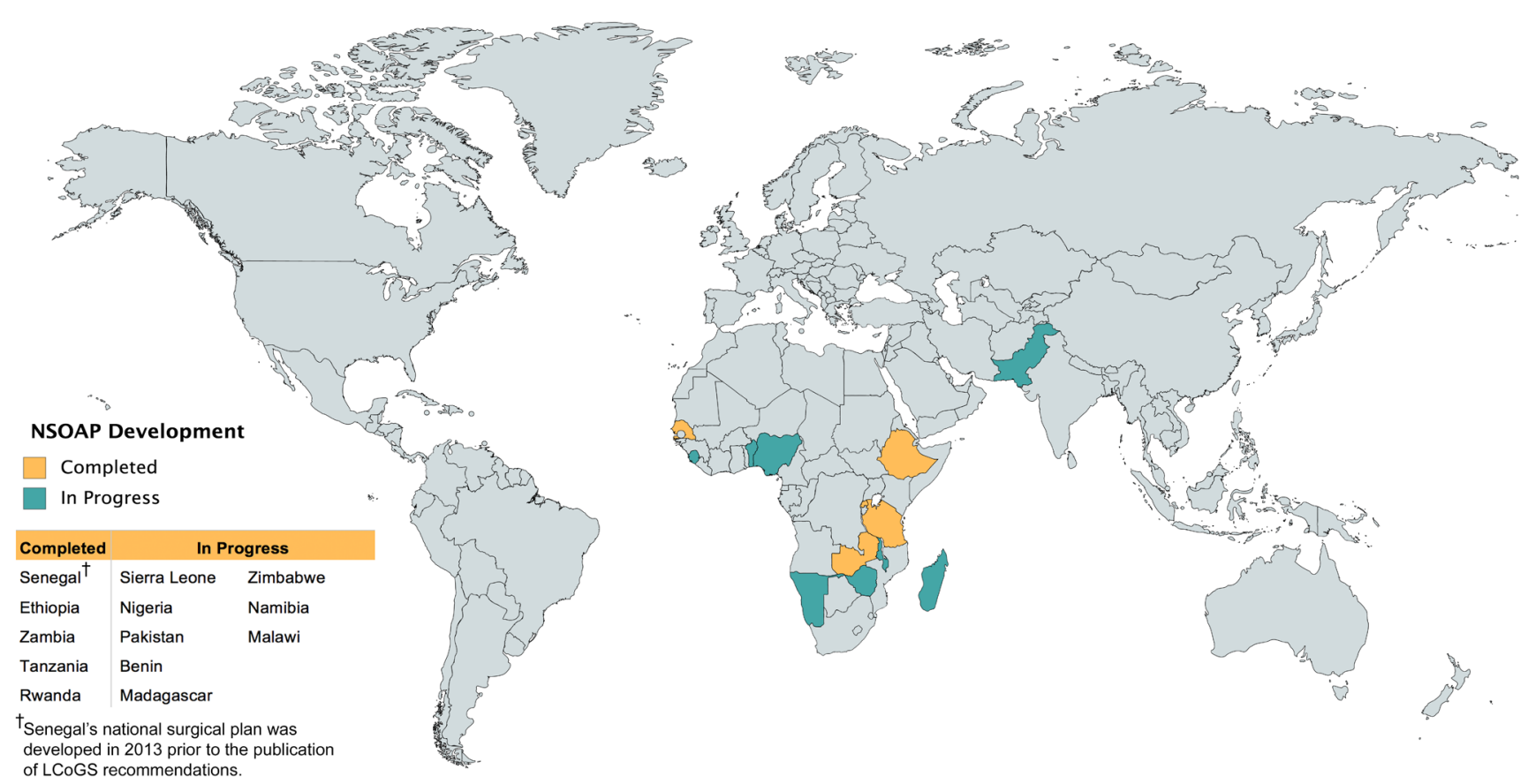

Figure 2 World map highlighting countries at various stages of the National Surgical, Obstetric, and Anesthesia Plans (NSOAP) development process. Additionally, more than a dozen other countries (not listed here) are considering the development of an NSOAP. LCoGS, Lancet Commission on Global Surgery.

Yet, there is no large-scale, concerted effort to address this problem. We posit that these converging priorities can be better achieved by working together as both stakeholders are critical to the development of resilient surgical systems. Given the recent advancement in both DRR and global surgery, a window of opportunity exists to develop integrated policy. We present three key opportunities for collaboration, which are summarised in box 1 .

\section{Separate frameworks, common goals}

In 2015, the LCoGS and the Sendai Framework for Disaster Risk Reduction independently set forth roadmaps to achieve global surgery and DRR goals. The LCoGS identified metrics and created the framework to increase access to safe, timely

\section{Box 1 Key messages summarising converging priorities} for surgical and disaster planning

- The Lancet Commission on Global Surgery and the Sendai Framework for Disaster Risk Reduction promote similar objectives because they both focus on health system strengthening in low/ middle-income countries (LMIC), and are explicitly linked by the integral role of surgical systems in delivering timely, effective disaster response.

- National Surgical, Obstetric, and Anesthesia Plans (NSOAPs) and disaster risk reduction (DRR) strategies should be developed in concert by identifying and addressing surgical system requirements.

- Recent momentum for NSOAPs in LMICs represents a political window for the integration and development of DRR strategies that address surgical care. and affordable surgical services. ${ }^{12}$ The Sendai Framework introduced a process for improving national disaster resilience. ${ }^{5}$ The key objectives of both movements ultimately rely on health system strengthening in LMICs. Additionally, as presented earlier, these two frameworks are explicitly linked by the central position of local surgical systems in ensuring timely and effective disaster response. Figure 3 presents the key domains of the LCoGS NSOAP framework and the Sendai Framework priorities.

\section{Integration of the surgical and disaster planning processes}

In addition to sharing common goals, the two frameworks propose individual national-level planning mechanisms. The Sendai Framework supports the development

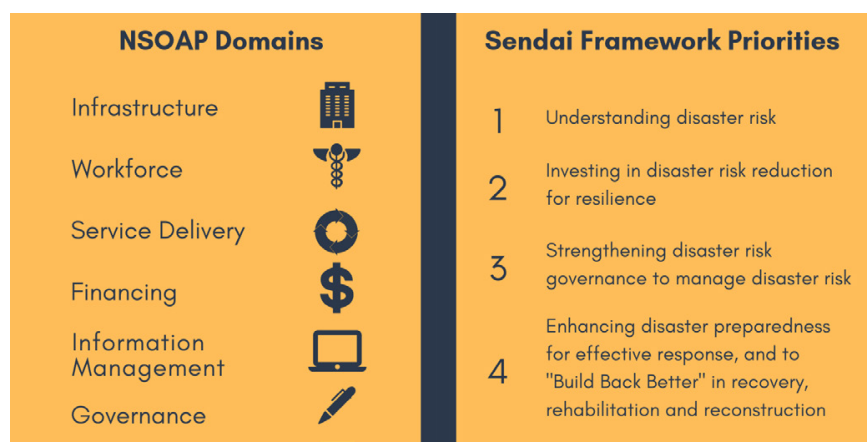

Figure 3 The key domains of the National Surgical, Obstetric, and Anesthesia Plans (NSOAP) framework as developed by the Lancet Commission on Global Surgery and the priorities identified by the United Nations (UN) Sendai Framework for Disaster Risk Reduction. 
of national DRR strategies, whereas the LCoGS recommends development of NSOAPs. ${ }^{5}{ }^{12}$ Given the overlapping goals, stakeholders and analogous processes, planning should be coordinated.

The process of planning a DRR strategy includes two core elements which directly intersect with national surgical planning: stakeholder organisation and risk analysis. DRR strategies begin with an organising process designed to gather and align stakeholders. Ideally, this should include relevant surgical leaders in addition to disaster response and policy leaders. The Health Emergency and Disaster Risk Management (Health-EDRM) is an existing WHO-supported framework which aligns health and disaster risk management. Adding surgery to the Health-EDRM agenda could further facilitate stakeholder engagement, promote integrated health system planning and incorporate essential surgical system components into the DRR planning process. ${ }^{50}$

Knowing the baseline surgical capacity is essential for an accurate evaluation of disaster risk. The NSOAP planning process uses key surgical indicators and a situational analysis tool to understand the surgical system and surgical care in detail. ${ }^{51}$ Thus, national DRR strategies can use NSOAP-derived surgical baseline data to identify disaster-related vulnerabilities in the local surgical system. A resilience index recently proposed by Kruk $e t$ al may be useful for this purpose as it outlines the components of a resilient health system.$^{39}$ Additionally, reporting on disaster-specific vulnerabilities could describe key needs for adequate infrastructure (eg, operating room availability, electricity, radiology services, and so on) or sufficient workforce levels (eg, surgical, obstetric, anaesthesia staff density, availability of neurosurgical and orthopaedic services, and so on).

In this fashion, future versions of country-specific NSOAPs can draw on this DRR vulnerability analysis to buttress components of the surgical system that are susceptible to disasters. Recognizing that disasters are not bound by national borders, we recommend that the disaster management community prioritise risk reduction recommendations that are tailored to individual NSOAPs and integrated with transnational and regional approaches to health policy.

\section{NSOAPs and natural disasters are policy windows}

Since the Global Surgery 2030 report recommended national strategic planning to develop surgical care policy, the current political priorities in global surgery have emphasised development along the six major domains of surgical systems. ${ }^{51}$ This recent momentum for national surgical planning (ie, NSOAPs) in LMICs represents an opportunity to integrate DRR strategies into surgical systems. In the past 2 years, 4 NSOAPs have been completed, 10 more plans are underway and an additional 23 countries have committed to developing their own. ${ }^{1251}$

Although this proposed collaborative process would ideally occur prior to disasters, the Sendai Framework recognises that each disaster represents an opportunity to 'build back better' by mobilising newly available resources and political priority to advance health system development. This is particularly relevant in countries without an existing NSOAP; crisis presents a chance to initiate such a planning process. By integrating surgical system planning with DRR strategies after disaster, global surgery and disaster management stakeholders can promote the development of surgical systems, a process which may not have had the adequate political priority beforehand. As postdisaster reconstruction efforts have historically failed to capitalise on this opportunity, we propose this collaborative process as an avenue to not only 'build back better' but also to build back together. ${ }^{38}$

\section{CONCLUSION}

Given the widespread impact, increasing frequency and profound effects of disasters on LMIC populations, a health system strengthening strategy is necessary to mitigate their devastating effects. Key to this approach is developing robust local surgical capacity that is resilient to the additional stresses of peridisaster situations. To achieve this, meaningful collaboration between the disaster management and global surgery stakeholders is necessary.

The LCoGS and the Sendai Framework advocate for key objectives related to health system strengthening in LMICs, and the current momentum around the development of NSOAPs presents a unique window to align stakeholders and advance common policy. We strongly urge interdisciplinary collaboration to deconstruct the existing policy silos which currently separate these similar efforts to strengthen health systems. Working together, as surgeons, DRR experts and policymakers, we can develop surgical systems that limit avertable suffering and death caused in disasters.

\section{Author affiliations \\ ${ }^{1}$ Program in Global Surgery and Social Change, Harvard Medical School Department of Global Health and Social Medicine, Boston, Massachusetts, USA ${ }^{2}$ Department of Surgery, Beth Israel Deaconess Medical Center, Boston, Massachusetts, USA \\ ${ }^{3}$ Tufts University School of Medicine, Boston, Massachusetts, USA \\ ${ }^{4}$ University of Miami School of Medicine, Miami, Florida, USA \\ ${ }^{5}$ Department of Surgery, Vanderbilt University Medical Center, Nashville, Tennessee, USA \\ ${ }^{6}$ Humanitarian Response Program, US Naval War College, Newport, Rhode Island, USA \\ ${ }^{7}$ Plastic and Oral Surgery, Boston Children's Hospital, Boston, Massachusetts, USA}

Contributors JP and RHP contributed equally to this paper. JP, RHP, LC, TW, RK and DSC conceived the manuscript. All authors contributed to the analysis. JP, RHP, LC, TW and DSC drafted the manuscript. RK, DP, BC and JGM provided critical review and final approval. All authors agreed to be accountable for all aspects of the work.

Funding RK reports grants from Ronda Stryker and William Johnston Global Surgery Fellowship Fund at Harvard Medical School, Boston, MA, USA, outside the submitted work. The Program in Global Surgery and Social Change at Harvard Medical School reports support from Monitoring and Evaluation for GE 
S2020-Developing Health Globally, a GE Safe Surgery Grant, and from the Steven C. and Carmella R. Kletjian Foundation, both outside the submitted work.

Competing interests None declared.

Patient consent for publication Not required.

Provenance and peer review Not commissioned; externally peer reviewed.

Data availability statement № additional data are available.

Open access This is an open access article distributed in accordance with the Creative Commons Attribution Non Commercial (CC BY-NC 4.0) license, which permits others to distribute, remix, adapt, build upon this work non-commercially, and license their derivative works on different terms, provided the original work is properly cited, appropriate credit is given, any changes made indicated, and the use is non-commercial. See: http://creativecommons.org/licenses/by-nc/4.0/.

\section{REFERENCES}

1. Liu C, Linde AT, Sacks IS. Slow earthquakes triggered by typhoons. Nature 2009;459:833-6.

2. Below R, Wallemacq P, Centre for Research on the Epidemiology of Disasters. Annual disaster statistical review 2017, 2018. Available: https://www.cred.be/annual-disaster-statistical-review-2017

3. Shepherd A, Mitchell T, Lewis K, et al. The geography of poverty, disasters and climate extremes in 2030, 2013. Available: https:// www.odi.org/sites/odi.org.uk/files/odi-assets/publications-opinionfiles/8637.pdf

4. United Nations Office for Disaster Risk Reduction. Terminology on disaster risk reduction, 2017. Available: https://www.unisdr.org/we/ inform/terminology

5. United Nations Office for Disaster Risk Reduction (UNISDR). Sendai framework for disaster risk reduction 2015-2030, 2015. Available: https://www.unisdr.org/we/inform/publications/43291

6. Rentschler JE. Why resilience matters - the poverty impacts of disasters. Policy Research Working Papers 2013.

7. Quarantelli EL. Implications for programmes and policies from future disaster trends. Risk Manag 1999;1:9-19.

8. Alexander D. Globalization of disaster: trends, problems and dilemmas. J Int Aff 2006;59:1-22.

9. Mazurana D, Benelli P, Feinstein International Center, Tufts University. Sex \& Age Matter: Improving Humanitarian Response in Emergencies, 2011. Available: https://www.fsnnetwork.org/sex-agematter-improving-humanitarian-response-emergencies\%C2\%AO

10. Traub M, Bradt DA, Joseph AP. The surge capacity for people in emergencies (scope) study in Australasian hospitals. Med J Aust 2007:186:394-8.

11. Lennquist S. Management of major accidents and disasters: an important responsibility for the trauma surgeons. The Journal of Trauma: Injury, Infection, and Critical Care 2007;62:1321-9.

12. Meara JG, Leather AJM, Hagander L, et al. Global surgery 2030: evidence and solutions for achieving health, welfare, and economic development. The Lancet 2015;8:569-624.

13. Trelles Centurion M, Crestani R, Dominguez L, et al. Surgery with limited resources in natural disasters: what is the minimum standard of care? Curr Trauma Rep 2018;4:89-95.

14. Man RX-G, Lack DA, Wyatt CE, et al. The effect of natural disasters on cancer care: a systematic review. Lancet Oncol. 2018;19:e482-99.

15. Demaio A, Jamieson J, Horn R, et al. Non-communicable diseases in emergencies: a call to action. PLoS Curr 2013;5.

16. Giri S, Risnes K, Uleberg O, et al. Impact of 2015 earthquakes on a local hospital in Nepal: a prospective hospital-based study. Plos One 2018;13:e0192076.

17. Reifels $L$. Reducing the future risk of trauma: on the integration of global disaster policy within specific health domains and established fields of practice. IJERPH 2018;15.

18. Murray V, Aitsi-Selmi A, Blanchard K. The role of public health within the United Nations post-2015 framework for disaster risk reduction. Int J Disaster Risk Sci 2015;6:28-37.

19. von Schreeb J, Riddez L, Samnegård $\mathrm{H}$, et al. Foreign field hospitals in the recent sudden-onset disasters in Iran, Haiti, Indonesia, and Pakistan. Prehosp Disaster Med 2008;23:144-51.

20. Cartwright $C$, Hall M, Lee ACK. The changing health priorities of earthquake response and implications for preparedness: a scoping review. Public Health 2017;150:60-70.

21. UN General Assembly. A/RES/36/225. Strengthening the capacity of the United Nations system to respond to natural disasters and other disaster situations, 1981. Available: http://www.un.org/documents/ ga/res/36/a36r225.htm
22. Norton I, von Schreeb J, World Health Organization. Classification and minimum standards for foreign medical teams in sudden onset disasters, 2013. Available: http://www.who.int/entity/csr/resources/ publications/ebola/foreign-medical-teams/en/index.htm

23. Pretto EA, Safar P. National medical response to mass disasters in the United States. JAMA 1991;266:1259-62.

24. Jang $\mathrm{H}-\mathrm{C}$, Lien $\mathrm{Y}-\mathrm{N}$, Tsai T-C. Rescue information system for earthquake disasters based on MANET emergency communication platform. Proceedings of the 2009 International Conference on Wireless Communications and Mobile Computing: Connecting the World Wirelessly, 2009.

25. Hayes GP, Meyers EK, Dewey JW, et al. Tectonic summaries of magnitude 7 and greater earthquakes from 2000 to 2015. U.S. geological survey, 2017. Available: http://pubs.er.usgs.gov/ publication/ofr20161192

26. Rodriguez-Llanes JM, Hellman L, Wu Q, et al. Time to include burden of surgical injuries after disasters in the global surgery agenda? An assessment of DALYs and averted burden by surgery after the 2008 Wenchuan earthquake. BMJ Glob Health 2018:3:e000909.

27. Mclntyre T, Hughes CD, Pauyo T, et al. Emergency surgical care delivery in post-earthquake Haiti: partners in health and Zanmi Lasante experience. World J Surg 2011;35:745-50.

28. Shi Y-kang, Wang L-lan, Lin Y-dan, et al. Challenges for rear hospital care of Wenchuan earthquake casualties: experience from West China Hospital. Chin J Traumatol 2010;13:131-6.

29. UN General Assembly. Measures to be adopted in connexion with the earthquake in Iran, 1963. Available: https://www.preventionweb. net/files/resolutions/NR019261.pdf

30. UN General Assembly. Assistance in cases of natural disaster and other disaster situations, 1971. Available: http://www.un.org/ documents/ga/res/26/ares26.htm

31. UN General Assembly. A/RES/42/169. International decade for natural disaster reduction, 1987. Available: http://www.un.org/ documents/ga/res/42/a42r169.htm

32. World Conference on Natural Disaster Reduction. Yokohama strategy and plan of action for a safer world: guidelines for natural disaster prevention, preparedness and mitigation. International decade of disaster reduction, 1994. Available: https://www.unisdr. org/we/inform/publications/8241

33. International Decade for Natural Disaster Reduction. Programme forum of international decade for natural disaster reduction opens in Geneva, 1999. Available: https://www.un.org/press/en/1999/ 19990707.IHA682.html

34. UN General Assembly. International decade for natural disaster reduction: successor arrangements, 2000. Available: http://eird.org/ fulltext/GA-resolution/a-res-54-219-eng.pdf

35. United Nations Office for Disaster Risk Reduction. Living with risk: a global review of disaster reduction initiatives, 2004. Available: https://www.unisdr.org/we/inform/publications/657

36. UN General Assembly. 60/196. natural disasters and vulnerability, 2005. Available: http://www.un.org/en/ga/search/view_doc.asp? symbol=A/RES/60/196

37. UN General Assembly. 61/198. International strategy for disaster reduction, 2006. Available: http://www.un.org/en/ga/search/view_ doc.asp?symbol=A/RES/61/198\&Lang=E

38. Hallegatte S, Maruyama Rentschler JE, Walsh BJ. Building back better: achieving resilience through stronger, faster, and more inclusive post-disaster reconstruction. The World Bank, 2018: 1-47.

39. Kruk ME, Ling EJ, Bitton A, et al. Building resilient health systems: a proposal for a resilience index. BMJ 2017;23

40. Coventry CA, Vaska Al, Holland AJA, et al. Surgical procedures performed by emergency medical teams in Sudden-Onset disasters: a systematic review. World J Surg 2019;43:1226-31.

41. World Health Assembly. WHA 68.15: strengthening emergency and essential surgical care and anaesthesia as a component of universal health coverage, 2015. Available: http://apps.who.int/gb/ebwha/pdf files/wha68/a68_r15-en.pdf

42. Debas HT, Donkor P, Gawande A, et al. Disease control priorities. Volume 1. Third Edition. World Bank, 2015.

43. Alkire BC, Raykar NP, Shrime MG, et al. Global access to surgical care: a modelling study. The Lancet Global Health 2015;3:e316-23.

44. Kim J. Transcript of recorded video remarks by Jim Yong Kim, president of the world bank group, to the Lancet Commission on global surgery, 2014. Available: http://www.globalsurgery.info/wpcontent/uploads/2014/01/Jim-Kim-Global-Surgery-Transcribed.pdf

45. The United Republic of Tanzania Ministry of Health, Community Development, Gender, Elderly and Children. National Surgical, Obstetric, and Anaesthesia Plan (NSOAP) 2018 - 2025, 2018. Available: https://docs.wixstatic.com/ugd/d9a674_4daa353b7306 4f70ab6a53a96bb84ace.pdf 
46. Federal Ministry of Health of Ethiopia. National five years safe surgery strategic plan, 2016. Available: https://docs.wixstatic.com/ ugd/d9a674_2ee52716f17f4ac4b1152f3b06aec61b.pdf

47. Republic of Zambia Ministry of Health. National surgical, obstetric, and anaesthesia strategic plan (NSOASP), 2017. Available: https:// docs.wixstatic.com/ugd/d9a674_70f6813fe4e74c4d99eb0283 36a38745.pdf

48. Sonderman KA, Citron I, Meara JG. National surgical, obstetric, and anesthesia planning in the context of global surgery. JAMA Surg 2018;153:959-60.

49. Republic of Rwanda. National surgical, obstetrics, and anesthesia plan 2018-2024, 2018. Available: https://docs. wixstatic.com/ugd/ d9a674_c5c36059456a416480fd58fd553ef302.pdf
50. Lo STT CEYY, Chan GKW, Murray V, et al. Health emergency and disaster risk management (Health-EDRM): developing the research field within the Sendai framework paradigm. Int J Disaster Risk Sci 2017:8:145-9.

51. Albutt K, Citron I, Sonderman K, et al. National Surgical Obstetric and Anaesthesia Planning: Process and Consensus Recommendations. Harvard Medical School Center for Global Health Delivery - Dubai, 2018. Available: https://ghd-dubai.hms. harvard.edu/files/ghd_dubai/files/2018-dubai_nsoap_policy_brief. pdf? $m=1525866968$ 